\title{
Does vitreous fluorophotometry reflect severity of early diabetic retinopathy?*
}

\author{
W E PLEHWE, $\dagger$ M A SLEightholm, and E M KOHNER \\ From the Department of Medicine, Royal Postgraduate Medical School, Hammersmith Hospital, London
}

SUMMARY To determine the relationship between vitreous fluorophotometry (VF) and severity of diabetic retinopathy (DR) 13 patients with mild to moderate background DR starting continuous subcutaneous insulin infusion were followed up serially for 12 months. They were studied by colour stereo retinal photographs, which were assessed by the Wisconsin Grading System, and by VF, which was assessed by the permeability index of the retina for fluorescein. By four months the severity of DR on colour photographs had deteriorated by at least one level in at least one eye in eight patients. In four patients the DR did not deteriorate. Assessment of anatomical abnormalities by severity of DR on colour photographs correlated well with the functional abnormalities of the blood-retinal barrier(s) assessed by VF, especially for the macular field. Comparison of permeability index data in the patients developing preproliferative or proliferative features of DR (group A) with the same data in patients who did not develop such changes (group B) indicated that group A patients had more severe DR than did group B patients at entry. Grading of colour photographs showed a similar trend but with greater overlap. Considerable overlap in fluorescein permeability remained between those subjects with no visible DR and those with microaneurysms with or without haemorrhages and small hard exudates.

Vitreous fluorophotometry (VF) was developed 20 years ago $^{1}$ in the expectation that it would enable a functional abnormality to be identified in patients at risk of developing diabetic retinopathy (DR) prior to the appearance of overt structural abnormalities. Early studies ${ }^{2-5}$ suggested that this might indeed be the case. However, several groups found considerable overlap between patients with no or minimal retinopathy and the normal range, ${ }^{6-8}$ despite the use of standardised equipment (Fluorotron Master, Coherent Radiation, Palo Alto, CA) and rigorous mathematical analysis of the data obtained. ${ }^{9}$ Since only small anatomical differences are present between subjects with no DR and those with minimal DR, correlation was then sought between the degree of fluorescein permeability of the blood-retinal barrier(s) measured by VF, and severity of the structural

Correspondence to Professor E M Kohner, Department of Medicine, Royal Postgraduate Medical School, Hammersmith Hospital, Du Cane Road, London W12 0HS.

*Presented in part at ARVO, Sarasota FL, May 1988.

†Present address: Department of Medicine, Monash University, Prince Henry's Hospital, St Kilda Road, Melbourne 3004, Victoria, Australia. abnormalities through a larger range of patients encompassing mild to moderate background DR. Patients beginning treatment with continuous subcutaneous insulin infusion (CSII) were selected for study, since earlier reports indicated that significant retinal changes might be observed within a few months of starting CSII. ${ }^{10-12}$

\section{Patients and methods}

Thirteen consecutive patients attending the Diabetic Retinopathy Clinic, Hammersmith Hospital, who also accepted CSII were included in the study. Patients with ketosis-prone insulin-dependent diabetes of at least five years' duration and with background DR were studied, who were otherwise in good health and normotensive with diastolic blood pressures not exceeding $90 \mathrm{mmHg}$. They received no treatment other than insulin. The patients were admitted to the Metabolic Unit of the hospital for three to four days for familiarisation with the infusion device and for serial monitoring of capillary blood glucose concentrations (BM 20-800R sticks, Boehringer Mannheim). Before starting CSII all the 
patients were examined by indirect and direct ophthalmoscopy and slit-lamp biomicroscopy to exclude posterior vitreous detachment, and stereo colour photographs of the seven standard fields of the Diabetic Retinopathy Study ${ }^{13}$ were taken. Fluorescein angiography and vitreous fluorophotometry were performed at the same time, and blood was taken for estimation of total glycosylated haemoglobin $\left(\mathrm{HbA}_{1}\right)$ by gel electrophoresis (Glytrac kits, Corning, Palo Alto, CA). These investigations were repeated after one, four, and 12 months of CSII treatment, and $\mathrm{HbA}_{1}$ was measured at eight months in addition.

Stereo retinal colour photographs were graded by comparison with the standard photographs of the Diabetic Retinopathy Study Research Group ${ }^{13}$ by an observer who was masked as to patient identity and to sequence of the photographs. Levels of severity of DR were assigned according to the criteria of the Wisconsin Study ${ }^{14}$ as modified by Canny et al. ${ }^{15}$ This provided a standardised anatomical assessment of the severity of retinopathy. Briefly, levels of severity corresponded to the following lesions:

Level 10: no retinopathy.

Level 20: microaneurysms only.

Level 30: microaneurysms and at least one of haemorrhages, small hard exudates, venous loops, questionable cotton-wool spots (CWS), questionable intraretinal microvascular abnormalities (IRMA), and questionable venous beading (VB).

Level 40: microaneurysms and at least one of definite CWS, definite IRMA, definite VB, moderate or large hard exudates, or severe haemorrhages.

Level 50: combinations of severe haemorrhages, CWS, IRMA and VB in the four peripheral fields.

Level 60: neovascularisation or fibrous tissue associated with new vessels, or photocoagulation for neovascularisation.

Vitreous fluorophotometry was performed on both eyes by means of the Fluorotron Master (Coherent Radiation, Palo-Alto, Calif) during the one hour after bolus intravenous injection of $14 \mathrm{mg} / \mathrm{kg} 20 \%$ sodium fluorescein angiography. Fluorophotometry data were analysed initially using the optimised protocol supplied by the manufacturer. From the data and from measurement of plasma-free (nonprotein bound) fluorescein a permeability index for fluorescein of the blood-retinal barrier(s) of the perimacular retina was derived, as described previously.$^{16}$ This provided an assessment of the functional abnormalities due to DR and allowed comparison with the structural abnormalities observed on retinal photographs. Units of permeability index were $10^{-7} \mathrm{~cm} \cdot \mathrm{s}^{-1}$. The concentration of fluorescein glucuronide ${ }^{17-19}$ was considered in concentration equivalents of fluorescein, on the assumption that the transport rates of free fluorescein and free fluorescein monoglucuronide across the blood-retinal barrier(s) were equal. ${ }^{2021}$

Patients were separated into those who within four months showed deterioration, with the appearance of new preproliferative (CWS or IRMA) or proliferative features (group A), and those who did not deteriorate or in whom change was limited to the appearance of haemorrhage in eyes in which DR was characterised previously by the presence of microaneurysms alone (group B). Severity of retinopathy was compared with the permeability index. The mean of the permeability index for the right and left eye was used for each patient, and values were logtransformed to obtain a normal distribution. Mean values of the log-transformed permeability index for all visits for all patients were then plotted against level of severity of DR. Finally, to determine the relative importance of DR in the macular field alone compared with that of the eye as a whole in leading to elevation of the permeability index, all logtransformed permeability index data were also plotted against level of DR in the macular field (field 2).

Approval for the study was obtained from the Ethics Committee, Hammersmith Hospital, and all patients gave informed consent prior to entry.

Unless stated otherwise, the statistical significance of differences between groups was assessed by Student's paired and unpaired $t$ test, as appropriate. The relationship of PI to retinopathy severity was studied by $\chi^{2}$ and Kruskar-Wallis tests.

\section{Results}

Of the 13 subjects only two were female. One of these developed florid neovascularisation at four months and required bilateral panretinal photocoagulation. Two other patients did not complete 12 months of study; one departed permanently from the UK after the four-month assessment, and the other died suddenly of lung carcinoma prior to the four-month assessment. Vitreous fluorophotometry data on the latter patient at one month could not be recovered from a faulty computer disc, and this patient was excluded from the analysis. All other patients completed 12 months of CSII treatment successfully.

PROGRESSION OF DR BY GRADING OF COLOUR PHOTOGRAPHS

Severity of DR at entry was assessed at level 20 in four eyes of two patients, at level 30 in nine eyes of six patients, and at level 40 in the remaining 11 eyes of eight patients. Patients who deteriorated were compared with those whose DR remained at a milder 
Table 1 'Severity of retinopathy in patients beginning CSII

\begin{tabular}{lllll}
\hline \multirow{2}{*}{ Patient } & Entry & \multicolumn{3}{c}{ Months of study } \\
\cline { 3 - 5 } & & 1 & 4 & 12 \\
\hline Group $A$ & & & & \\
1 & 7 & 7 & 8 & 8 \\
2 & 6 & 7 & 7 & 7 \\
3 & 7 & 8 & 11 & $*$ \\
4 & 6 & 7 & 6 & 7 \\
5 & 6 & 7 & 6 & - \\
6 & 6 & 6 & 7 & 5 \\
7 & 5 & 5 & 7 & \\
Group B & & & & \\
8 & 3 & 4 & 3 & 4 \\
9 & 5 & 5 & 5 & 6 \\
10 & 6 & 5 & 5 & 5 \\
11 & 7 & 6 & 7 & 7 \\
12 & 3 & 3 & 3 & 3 \\
\hline
\end{tabular}

${ }^{*}$ Required photocoagulation.

Severity is adapted from the method of Canny et al. ${ }^{15}$ keyed to the worse eye. Level $10 / 10=1,20 / 10=2,20 / 20=3,30 / 20=4,30 / 30=5$, $40 / 30=6,40 / 40=7,50 / 40=8,50 / 50=9,60 / 50=10,60 / 60=11$.

level by the step-wise system of grading severity keyed to the worse eye ${ }^{15}$ (Table 1 ). By four months a total of eight patients had deteriorated by at least one level in at least one eye, and, of these, seven had developed new CWS, IRMA, or neovascularisation. In the remaining patient, deterioration was restricted to the appearance of haemorrhage in an eye in which

Table 2 Mean retinal permeability index by vitreous fluorophotometry

\begin{tabular}{llll}
\hline Patient & Entry & \multicolumn{3}{l}{ Months of study } \\
\cline { 2 - 4 } & 1 & 4 & 12 \\
\hline
\end{tabular}

\begin{tabular}{|c|c|c|c|c|}
\hline \multicolumn{5}{|l|}{ Group A } \\
\hline 1 & $10 \cdot 1$ & $14 \cdot 4$ & $13 \cdot 7$ & $8 \cdot 25$ \\
\hline 2 & 6.44 & $3 \cdot 01$ & 8.87 & $10 \cdot 7$ \\
\hline 3 & $19 \cdot 9$ & $20 \cdot 7$ & $65 \cdot 8$ & - \\
\hline 4 & $2 \cdot 66$ & $3 \cdot 01$ & $2 \cdot 23$ & 3.96 \\
\hline 5 & 3.91 & 1.92 & $6 \cdot 18$ & 1.90 \\
\hline 6 & 3.95 & $2 \cdot 47$ & $2 \cdot 69$ & - \\
\hline 7 & $3 \cdot 11$ & $5 \cdot 37$ & 8.05 & $3 \cdot 41$ \\
\hline Mean (SD): & $7 \cdot 15(6 \cdot 18)$ & $7 \cdot 27(7 \cdot 33)$ & $15 \cdot 36(22 \cdot 75)$ & 5.64 (3.68). \\
\hline \multicolumn{5}{|l|}{ Group B } \\
\hline 8 & $1 \cdot 37$ & 1.97 & $2 \cdot 15$ & $2 \cdot 71$ \\
\hline 9 & $2 \cdot 21$ & 1.75 & $2 \cdot 07$ & $2 \cdot 27$ \\
\hline 10 & $2 \cdot 14$ & $3 \cdot 24$ & $3 \cdot 10$ & $2 \cdot 77$ \\
\hline 11 & 3.73 & $3 \cdot 34$ & $2 \cdot 42$ & $4 \cdot 64$ \\
\hline 12 & $3 \cdot 11$ & $5 \cdot 37$ & 8.05 & $3 \cdot 41$ \\
\hline Mean (SD): & $2.34(0.86)$ & $2.48(0.75)$ & $2 \cdot 37(0.43)$ & $3.05(0.92)$ \\
\hline
\end{tabular}

Individual values $\left(10^{-1} \mathrm{~cm} . \mathrm{s}^{-1}\right)$ are mean of the right and left eye on each occasion (except patient 8 (entry) and patient 12 (entry and 1 month), which are for the right eye only).
Table 3 Permeability index and glycosylated haemoglobin: means $(S D)$

\begin{tabular}{|c|c|c|c|c|}
\hline \multirow[t]{2}{*}{ Group } & \multirow[t]{2}{*}{ Entry } & \multicolumn{3}{|c|}{ Months of study } \\
\hline & & 1 & 4 & 12 \\
\hline \multicolumn{5}{|c|}{ 1. log Permeability Index $\left(\mathrm{cm} \cdot \mathrm{s}^{-1}\right)$} \\
\hline A & $0.75(0.31)$ & $0.69(0.40)$ & $0.91(0.49)$ & $0.67(0.30)$ \\
\hline B & $0.35(0.15)^{*}$ & $0 \cdot 38(0 \cdot 13)$ & $0.37(0.07) \dagger$ & $0.47(0 \cdot 12)$ \\
\hline \multicolumn{5}{|c|}{ 2. Glycosylated haemoglobin (\%) } \\
\hline A & $11 \cdot 2(2 \cdot 0)$ & $9 \cdot 6(1 \cdot 3)$ & $8 \cdot 3(1 \cdot 7) \ddagger$ & $9 \cdot 8(0.6)$ \\
\hline B & $10 \cdot 3(0 \cdot 1)$ & $10 \cdot 0(1 \cdot 1)$ & $9 \cdot 7(2 \cdot 6)$ & $9.2(0.7)$ \\
\hline
\end{tabular}

${ }^{*} \mathrm{p}<0.05$ vs group A log-transformed permeability index at entry. $\dagger \mathrm{p}<0.05$ vs group A log-transformed permeability index at 4 months.

$\neq p<0.05$ vs group $\mathrm{A} \mathrm{HbA}_{1}$ at entry.

DR was previously at level 20 . This patient was considered together with those whose DR did not change by four months. Fluorescein angiograms in general showed qualitative deterioration in parallel with changes on colour photographs.

\section{RETINAL PERMEABILITY TO FLUORESCEIN BY} VITREOUS FLUOROPHOTOMETRY

Table 2 shows the mean permeability index for right and left eyes in each patient (except subject 8 -initial visit - and subject 12 - initial and one-month visits when data for the right eye only were obtained). Table 3 shows the mean permeability index and $\mathrm{HbA}_{1}$ data in group $\mathrm{A}$ (patients who deteriorated on colour photographs by four months) and in group $B$ (non-deteriorators). The mean of the logtransformed permeability indices at entry was significantly higher in group $\mathrm{A}$ than in group $\mathrm{B}$ $(p<0.05)$, with only one patient in group A falling into the normal range and one in group $B$ with a value above the upper limit of normal. Patients in group $A$ could not be distinguished from those in group B by consideration of the vitreous fluorescein concentrations $3 \mathrm{~mm}$ anterior to the retina, as obtained from the optimised protocol-adjusted measurement scans at $1 \mathrm{~h} .{ }^{22}$ As shown in Table 1, patients who deteriorated (group A) were noted to have slightly more severe DR at entry (steps 5, 6, 6, 6, 6, 7,7) than patients in group B (steps $3,3,5,6,7$ ), but this difference did not reach statistical significance (Mann-Whitney test statistic 25·5, p=0·17). Patients in group $\mathrm{A}$ also achieved a significant fall in $\mathrm{HbA}_{1}$ by four months, whereas $\mathrm{HbA}_{1}$ did not change significantly over the course of 12 months.

RELATIONSHIP BETWEEN PERMEABILITY INDEX AND RETINOPATHY LEVEL

Fig. 1 shows the relationship between the logarithm 


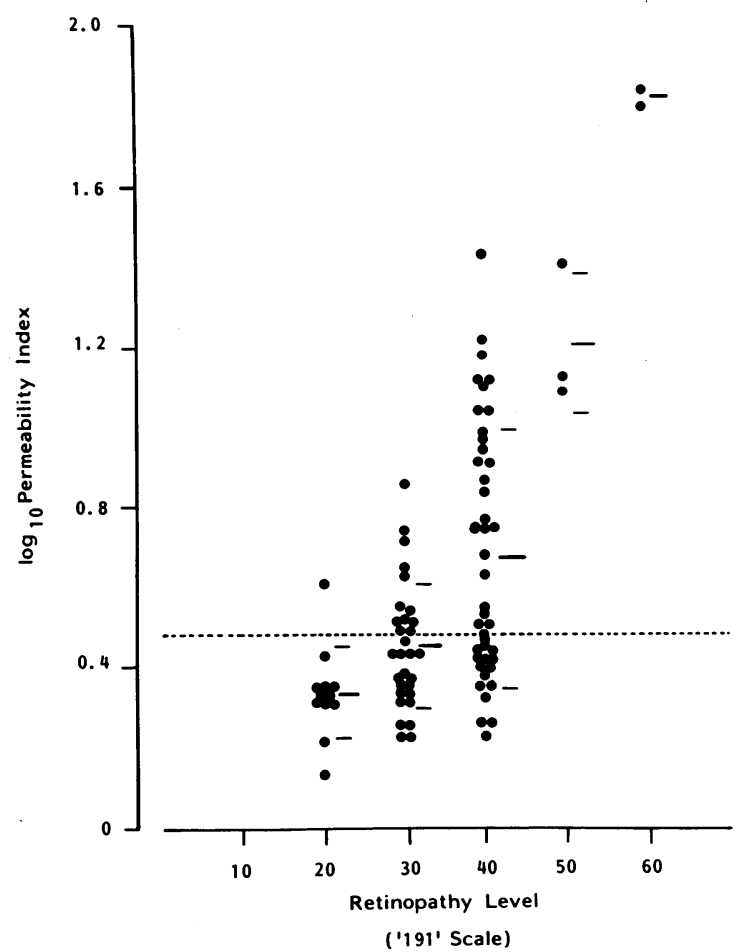

Fig. 1 Relationship between level of severity of retinopathy for individual eyes and the logarithm of the permeability index determined by vitreous fluorophotometry. The interrupted line indicates mean $+1 S D$ determined previously in normal subjects. ${ }^{16}$

of the permeability index and retinopathy level for all observations throughout the 12 months of study. The mean +1 SD of permeability index in normal subjects determined previously ${ }^{14}$ is shown as the interrupted line, and demonstrates clearly the large overlap between values obtained in eyes with mild DR and the normal range. The correlation of permeability index or its logarithm with level of severity of DR was highly significant statistically (Kruskal-Wallis statistic $=23.2, p<0.0001$ by $\chi^{2}$, values for levels 40,50 , and 60 being combined to avoid cells with small numbers of observations). Correlations of the severity of DR in the macular field (field 2) with permeability index was then sought. DR of level 50 is defined as a combination of preproliferative factors in four peripheral fields (superior and inferior temporal and nasal fields); hence this level did not apply. Results are shown in Fig. 2, and even better correlation was obtained statistically between the parameters (Kruskal-Wallis statistic $=38.9, \mathrm{p}<0.0001$, by $\chi^{2}$, values for levels 10 and 20 and levels 40 and 60 being combined to avoid cells with small numbers of observations).

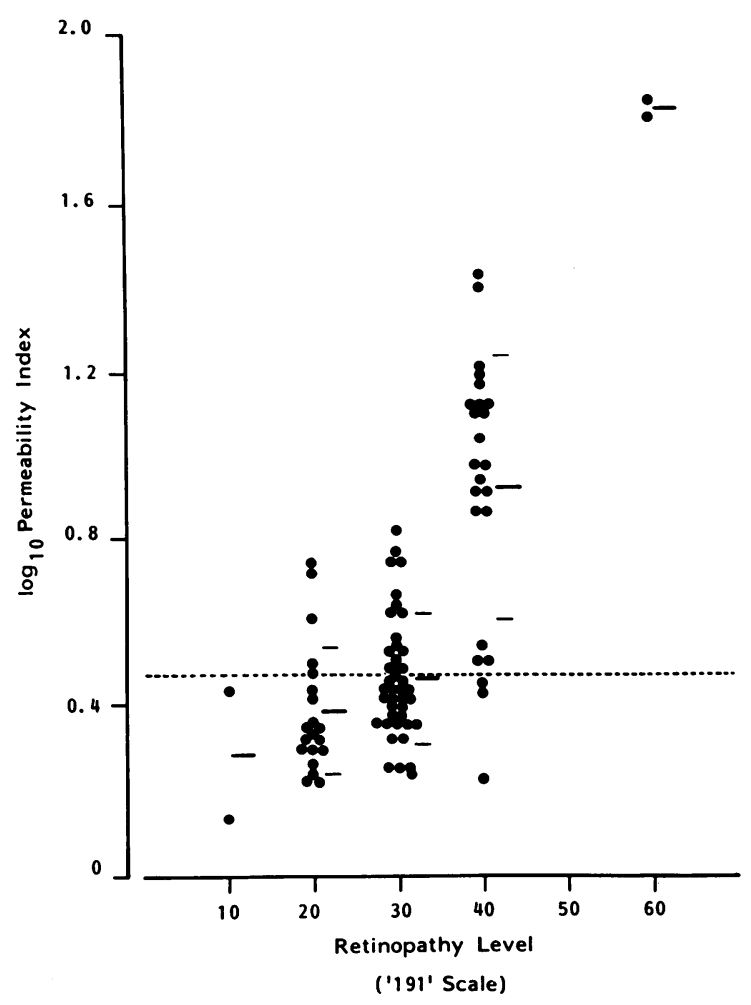

Fig. 2 Relationship between level of severity of retinopathy for the macular field (field 2) alone, and the logarithm of the permeability index determined by vitreous fluorophotometry. The interrupted line indicates mean $+1 S D$ determined previously in normal subjects. ${ }^{16}$

\section{Discussion}

This study confirms the results in a previous communication from this department in another group of patients, namely, that in those with no or minimal DR (levels 10, 20) the use of VF does not always demonstrate a difference from normal persons. ${ }^{9}$ In eyes with more severe DR (levels 30-60) the permeability index rose progressively, but some overlap remained between successive groups of patients. However, a good correlation between anatomical lesions (photographic severity) and the degree of the functional defect in the blood-retinal barrier(s) (measured by VF) existed at these more severe levels of DR.

A recent report from Chicago demonstrated a close relationship between the extent of disruption of the blood-retinal barrier of the perimacular retina, as measured by a posterior vitreous fluorophotometry penetration ratio, and visual acuity in patients with diabetic macular oedema. ${ }^{23}$ The amount of leakage 
also correlated well with the area of retinal thickening in the macular field as judged by grading of stereo colour retinal photographs. The results of the present study in patients with no visual loss due to macular oedema (except for patient 6 at four months) indicate a better correlation between the severity of DR in the macular field and the permeability index than between the severity of DR for the eye as a whole and the permeability index, and support the findings of Smith et al..$^{23}$ From the results of these studies it appears that vitreous fluorophotometry with Fluorotron Master will be of value as an additional investigation in diseases of the macula and perimacular retina rather than in conditions affecting the peripheral retina. It also suggests that one hour complete, even distribution of fluorescein may not have been obtained.

The exact pathogenesis of the deterioration of DR in patients beginning CSII remains to be determined. A variety of lesions including new vessels have been reported ${ }^{24}$ of which the most striking feature is the appearance of multiple CWS. ${ }^{1125}$ It has been suggested $^{1126}$ that the major causal factor was the rapid lowering of blood glucose concentrations (or changes of associated parameters) resulting indirectly in reduced retinal perfusion, leading to nerve fibre layer infarction and to the appearance of CWS. It is possible that other factors may contribute to the deterioration in these patients. Alternatively, ischaemia may be manifested in the appearance of IRMA and haemorrhages. In this study patients who deteriorated (group A) had a reduction in $\mathrm{HbA}_{1}$ by four months, whereas this was not observed in group B. It is therefore possible that, in this small series also, reduced blood glucose concentrations contributed to the deterioration of DR in group $A$.

In summary, the data presented suggest that subjects with disruption of the blood-retinal barrier(s), manifested as increased permeability of the perimacular retina to fluorescein, may be at higher risk of deterioration of DR after the institution of CSII, whereas those with milder DR may avoid such deterioration. Furthermore, the pooled data suggest a good correlation between the degree of functional abnormality measured by VF and the severity of structural lesions assessed by a standardised grading technique. The patient who required photocoagulation reconfirmed previous reports that institution of CSII with improved glycaemic control does not prevent the development of neovascularisation.

This work was supported in part by a Juvenile Diabetic Foundation International Postdoctoral Fellowship (WEP) and the British Diabetic Association Group Grant (EMK).

\section{References}

1 Cunha-Vaz JG, Maurice DM. The active transport of fluorescein by the retinal vessles and retina. J Physiol (Lond) 1967; 191: 467-86.

2. Cunha-Vaz JG, De Abreu JRF, Campos AJ, Figo G. Early breakdown of the blood-retinal barrier in diabetes. $\mathrm{Br} \mathrm{J} \mathrm{Oph}$ thalmol 1975; 59: 649-56.

3 Cunha-Vaz JG, Fonseca JR, Abreu JF, Ruas MA. A follow-up study by vitreous fluorophotometry of early retinal involvement in diabetes. Am J Ophthalmol 1978; 86: 467-73.

4 Waltman SR, Oestrich C, Krupin T, et al. Quantitative vitreous fluorophotometry. A sensitive technique for measuring early breakdown of the blood-retinal barrier in young diabetic patients. Diabetes 1978; 27: 85-7.

5 Cunha-Vaz JG, Fonseca JR, Abreu JF, Ruas MA. Detection of early retinal changes in diabetes by vitreous fluorophotometry. Diabetes 1979; 28: 16-9.

6 Krupin T, Waltman SR, Oestrich C, et al. Vitreous fluorophotometry in juvenile-onset diabetes mellitus. Arch Ophthalmol 1978; 96: 812-4.

7 Porta M, Townsend C, Clover JM, et al. Evidence for functional endothelial cell damage in early diabetic retinopathy. Diabetologia 1981; 20: 597-601.

8 Bursell SE, Delori FC, Yoshida A, Parker JS, Collas GD, McMeel JW. Vitreous fluorophotometric evaluation of diabetics. Invest Ophthalmol Vis Sci 1984; 25: 703-10.

9 Chahal P, Fallon TJ, Jennings SJ, Chowienczyk PJ, Kohner EM. Vitreous fluorophotometry in patients with no or minimal retinopathy. Diabetes Care 1986; 9: 134-9.

10 Lauritzen T, Frost-Larsen K, Larsen H-W, Deckert T, Steno Study Group. Effect of one year of near-normal blood-glucose levels on retinopathy in insulin-dependent diabetes. Lancet 1983; i: $200-4$.

11 Dahl-Jorgensen $\mathrm{K}$, Brinchmann-Hansen $\mathrm{O}$, Hansen KF, Sandvik L, Aagenaes O, Aker Diabetes Group. Rapid tightening of blood glucose control leads to transient deterioration in retinopathy in insulin-dependent diabetes mellitus. The Oslo Study. Br Med J 1985; 290: 811-5.

12 Kroc Collaborative Study Group. Blood glucose control and the evolution of diabetic retinopathy and albuminuria. $N$ Engl J Med 1985; 311: 365-72.

13 Diabetic Retinopathy Study Research Group. Report 7. A modification of the Airlie House classification of diabetic retinopathy. Invest Ophthalmol Vis Sci 1981; 21: 210-6.

14 Klein BEK, Davis MD, Segal P, et al. Diabetic retinopathy. Assessment of severity and progression. Ophthalmology 1984; 91: $10-7$.

15 Canny CLB, Kohner EM, Trautman J, Puklin J, Morse P for the Kroc Collaborative Study Group. Comparison of stereo fundus photographs in patients with insulin-dependent diabetes during conventional insulin treatment or continuous subcutaneous insulin infusion. Diabetes 1985; 34 (suppl 3): 50-5.

16 Chahal PS, Chowienczyk PJ, Kohner EM. Measurement of blood-retinal barrier permeability: a reproducibility study in normal eyes. Invest Ophthalmol Vis Sci 1985; 26: 977-82.

17 Chahal PS, Neal MJ, Kohner EM. Metabolism of fluorescein after intravenous injection. Invest Ophthalmol Vis Sci 1985; 26: 764-8.

18 Grotte D, Mattox V, Brubaker RF. Fluorescent, physiological and pharmacological properties of fluorescein glucuronide. Exp Eye Res 1985; 40: 23-34.

19 McLaren JW, Brubaker RF. Measurement of fluorescein and fluorescein glucuronide in the living human eye. Invest Ophthalmol Vis Sci 1986; 27: 966-74.

20 Kitano S, Nagataki S. Transport of fluorescein monoglucuronide out of the vitreous. Invest Ophthalmol Vis Sci 1986; 27: 998-1001.

21 Plehwe WE, Chahal PS, Fallon TJ, Cunningham JR, Neal MJ, Kohner EM. Role of fluorescein glucuronide and its metabolism in vitreous fluorophotometry. Exp Eye Res 1987; 44: 209-15. 
22 Roy MS, Bonner RF, Bungay PM, Podgor MJ, Collier B. Posterior vitreous fluorophotometry in normal subjects. Arch Ophthalmol 1986; 104: 1004-8.

23 Smith RT, Lee CM, Charles HC, Farber M, Cunha-Vaz JG. Quantification of diabetic macular edema. Arch Ophthalmol 1987; 105: 218-22.

24 Lawson PM, Champion MC, Canny CLB, et al. Continuous subcutaneous insulin infusion does not prevent progression of proliferative and preproliferative retinopathy. $\mathrm{BrJ}$ Ophthalmol 1982; 66: 762-6.
25 Lauritzen T, Frost-Larsen K, Larsen H-W, Deckert T, Steno Study Group. Two-year experience with continuous subcutaneous insulin infusion in relation to retinopathy and neuropathy. Diabetes 1985 ; 35 (suppl 3): 74-9.

26 Hanssen KF, Dahl-Jorgensen K, Lauritzen T, Feldt-Rásmussen B, Brinchmann-Hansen O, Deckert T. Diabetic control and diabetic complications: the near-normoglycaemic experience Diabetologia 1986; 29: 677-84.

Accepted for publication 23 June 1988. 